\title{
White Paper: Interventional MRI: Current Status and Potential for Development Considering Economic Perspectives, Part 2: Liver and Other Applications in Oncology
}

\author{
White Paper: Interventionelle MRT: Status Quo und \\ Entwicklungspotenzial unter ökonomischen Perspektiven, \\ Teil 2: Therapeutische und onkologische Anwendungen
}

Authors (alphabetical order)

Jörg Barkhausen', Thomas Kahn², Gabriele A. Krombach ${ }^{3}$, Christiane K. Kuhl ${ }^{4}$, Joachim Lotz ${ }^{5}$, David Maintz ${ }^{6}$, Jens Ricke, Stefan O. Schönberg ${ }^{8}$, Thomas J. Vogl ${ }^{9}$, Frank K. Wacker ${ }^{10}$

German Association of Chairmen in Academic Radiology (KLR)

G. Adam, G. Antoch, J. Barkhausen, M. Beer, T. Bley, A. Bücker, C. Düber, M. Forsting, B. Hamm, K. Hauenstein, W. Heindel, N. Hosten, O. Jansen, T. Kahn, H. U. Kauczor, G. A. Krombach, C. Kuhl, M. Langer, M. Laniado, J. Lotz, A. Mahnken, D. Maintz, K. Nikolaou, M. Reiser, J. Ricke, E. Rummeny, H. Schild, S. Schönberg, R. P. Spielmann, C. Stroszczynski, U. Teichgräber, M. Uder, T. J. Vogl, F. K. Wacker

\section{Affiliations}

1 Department of Radiology and Nuclear Medicine, University Hospital Schleswig Holstein Luebeck Campus, Germany

2 Clinic and Policlinic for Diagnostic and Interventional Radiology, Leipzig, Germany

3 Department of Radiology, University Hospital Giessen, Justus Liebig University, Giessen, Germany

4 Department of Diagnostic and Interventional Radiology, University Hospital RWTH Aachen, Germany

5 Institute for Diagnostic and Interventional Radiology, Georg-August-University Goettingen, Germany

6 Department of Radiology, University Hospital of Cologne, Cologne, Germany

7 Department of Radiology and Nuclear Medicine, University Hospital Magdeburg, Germany

8 Institute of Clinical Radiology and Nuclear Medicine, University Medical Center Mannheim, Medical Faculty Mannheim, University of Heidelberg, Mannheim, Germany

9 Department of Diagnostic and Interventional Radiology, University Hospital Frankfurt, Germany

10 Department for Diagnostic and Interventional Radiology, Hannover Medical School, Hannover, Germany

Key words

MR-guided interventions, MR-guided biopsy, MR-guided ablation, HIFU

received 15.02 .2017

accepted 08.05.2017
Bibliography

DOI https://doi.org/10.1055/s-0043-112336

Published online: 1.9.2017 | Fortschr Röntgenstr 2017; 189:

1047-1054 @ Georg Thieme Verlag KG, Stuttgart · New York, ISSN 1438-9029

Correspondence

Prof. Gabriele A. Krombach

Departrnent of Radiology

University Hospital Giessen, Justus Liebig University Giessen, Klinikstraße 33, 35392 Giessen, Germany

Tel.: ++49/641/98541800

Fax: ++ 49/641/98541809

gabriele.krombach@uniklinikum-giessen.de

\section{ABSTRACT}

Background MRI is attractive for guiding and monitoring interventional procedures due to its high intrinsic soft tissue contrast and the possibility to measure flow and cardiac function.

Methods Technical solutions have been developed for all procedural steps including imaging guidance, MR-safe catheters and instruments and patient monitoring. This has led to widening of the clinical applications. Interventional MRI is becoming increasingly important for the treatment of patients suffering from malignant diseases. The detectability of masses and consequently their accessibility for biopsy is higher, compared to other modalities, due to the high intrinsic soft tissue contrast of MRI. Temperature-dependent 
sequences allow for minimally invasive and tissue-sparing ablation (A-0 ablation).

Conclusion Interventional MRI has become established in the clinical routine for a variety of indications, including biopsies and tumor ablation. Since the economic requirement of covering costs by reimbursement is met and interventional MRI decreases the mortality and morbidity of interventional procedures, broader application of interventional MRI can be expected in the clinical routine in the future.

\section{Key points}

- Particularly for the treatment of oncological patients, interventional MRI is superior to other methods with respect to minimal invasiveness and tissue protection due to the ability to exactly determine tumor borders and to visualize and control the size of the ablation area on the basis of MR temperature measurement.

- Due to the better visualization of targets and the effects of ablation in tissue, interventional MRI can lower the mortality and morbidity associated with these interventions for many indications.

- The complex comparison of costs and reimbursement shows that this application can be performed in a costcovering manner and broader application can be expected in the future.

\section{Citation Format}

- Barkhausen J, Kahn T, Krombach GA et al. White Paper: Interventional MRI: Current Status and Potential for Development Considering Economic Perspectives, Part 2: Liver and Other Applications in Oncology. Fortschr Röntgenstr 2017; 189: 1047-1054

\section{ZUSAMMENFASSUNG}

Hintergrund Die interventionelle MRT mit den Vorteilen des hohen Weichteilkontrasts und der Temperatursensitivität sowie der freien Wahl der Schichtebene bietet Eigenschaften, die auch für die Behandlung von Patienten mit benignen Tumoren und mit Malignomen von besonderer Bedeutung sind.

Methoden Wir beschreiben die klinisch etablierten Verfahren der interventionellen MRT und die Entwicklungsperspektiven zur Behandlung von Patienten mit Malignomen und den Einsatz des HIFU für die Behandlung von benignen Tumoren wie Uterusmyomen.

Ergebnisse Technische Lösungen sind mittlerweile für alle prozeduralen Abläufe einschließlich der Bildsteuerung, und Instrumentensicherheit und Patientenüberwachung entwickelt worden. Dies hat dazu geführt, dass die Anwendungsfelder in der klinischen Routine erweitert wurden. Die interventionelle MRT spielt nun für die Behandlung onkologischer Patienten eine zunehmend wichtige Rolle. Tumore sind aufgrund des hohen Weichteilkontrastes im Vergleich zu anderen Modalitäten besser erkennbar und punktierbar. Ablationen können hierdurch gewebeschonend durchgeführt werden. Zudem ermöglicht der Einsatz temperatursensitiver Messmethoden die gezielte Einhaltung eines Sicherheitsabstandes (A-0 Ablation).

Schlussfolgerung Die interventionelle MRT ist im Rahmen der Biopsie und der ablativen Tumorbehandlung bereits in der klinischen Routine etabliert. Die genaue Kostenkalkulation und Gegenüberstellung zur Erlössituation zeigt, dass dieses Verfahren in seiner Gesamtheit kostendeckend durchgeführt werden kann. Aufgrund dieser ökonomischen Voraussetzungen und der Möglichkeit der Senkung von Mortalität und Morbidität für Patienten mit benignen und malignen Tumoren ist eine weitere Ausweitung des Einsatzes der interventionellen MRT in Zukunft zu erwarten.

\section{Introduction}

Interventional MRI is already part of the clinical routine for many areas of application such as breast and prostate biopsy as described in detail in the first part of this overview [1]. Because of the ability to clearly visualize tumor borders and to image the effects achieved by tumor ablation, this method is particularly important in the treatment of oncology patients. For comprehensive inclusion of the method in the clinical routine, it is still necessary to determine whether cost coverage can be ensured. All aspects of DRG billing must be included in such an analysis. This overview first describes interventional MRI methods and current fields of indication. MR-guided focused ultrasound is also taken into consideration here. A cost/reimbursement analysis showing cost coverage is performed at the end of the article on the basis of oncological application areas (MR-guided tissue ablation). Based on this, interventional MRI should be increasingly included in the clinical routine.

\section{Instruments and operating concepts for oncology}

The number of findings diagnosed on the basis of MR imaging in oncology patients and the options for the molecular characterization of tumors are increasing. Thus, the need to perform percutaneous interventions under MRI guidance is also increasing. In addition to use in the simple biopsy of tissue samples and aspirations [2-8], MR-guided treatment types such as sclerotherapy $[9,10]$, targeted injections [11-13], drainage $[14,15]$ and local tumor treatment $[16,17]$ have been described.

The first part of this overview discussed the freehand technique in open MRI [1]. Unfortunately, these horizontally open scanners are much less available than closed MRI scanners. The simplest way to perform interventions on a cylindrical MRI scanner is the single-step procedure as used in CT-guided interventions. To determine the location of a lesion and to monitor needle 
position, the patient must be moved into the isocenter of the MRI scanner and then moved back out of the scanner for incremental advancement of the needle using the freehand technique $[2,6]$. The interventions specified above require needles for aspiration, injection and biopsy that are visible on MRI, laser applicators, RF electrodes, and microwave antennas for ablation that are available from multiple manufacturers. The size of the instrument artifact depends among other things on the material, the magnetic field, and a series of sequence parameters. Therefore, individual adjustment of the parameters is essential. In addition to suitable instruments, a shielded monitor is needed in the magnet room and is commercially available both for $1.5 \mathrm{~T}$ and $3 \mathrm{~T} \mathrm{MRI}$ scanners. A series of tools have been developed to facilitate interventions in very narrow and long cylindrical magnets. For example, a control grid that is visible on the MRI image and allows a stereotactic approach has become established for breast biopsy [2]. MR-compatible robotic assistance systems intended to facilitate instrument placement in the magnet are more technically complicated [18 - 20]. Moreover, needle guides using augmented reality (AR) to project information acquired by the MRI scanner onto the patient lying directly in front of the magnet have been introduced [21-23]. Both robotic and AR systems are currently only used as prototypes and are not yet commercially available.

Compared to the stepwise approach with and without additional support systems, continuous imaging during MR-guided puncture in the "open" magnet has significant advantages. Puncture under real-time control is possible because most cylindrical MRI scanners have become shorter and have large openings $(>70 \mathrm{~cm})$ that allow access to the patient in or near the isocenter of the magnet and advancing of the needle under continuous MRI guidance $[8,13,24]$. This is also possible in the case of open MRI scanners with 2 horizontally arranged magnetic poles that allow good access to the patient depending on the diameter of the poles and the size of the opening between the poles. In the case of a small pole diameter, access is good but the quality of the almost real-time imaging is limited due to the low field strength of these systems [14, 25]. Horizontally open MRI scanners with higher field strengths provide higher image quality [12] but commercial availability is currently still limited. Regardless of the system design, MR imaging in real time in "open" magnets during puncture has several advantages: the free selection of slice orientation in MRI can be interactively used with the help of a water-filled syringe or a finger to find the body access point without a light localizer and/or marker; continuous imaging of the needle, puncture path, and target allows safe puncture; oblique puncture trajectories can be better maintained in the freehand technique; efficient puncture is possible $[2,4,13,26]$. Ideally the interactive adjustment of slice planes does not have to be performed manually but rather fully automatic adjustment to the orientation of the instruments is performed [27]. To facilitate needle tracking, interactive user interfaces for MR-guided interventions have been introduced $[4,27,28]$ some of which can also process coordinates from external navigation systems to adjust the slice orientation to the trajectory of the instrument. Moreover, efforts are being made to integrate instrument navigation, ablation planning software, and temperature monitoring into the MRI scanner to achieve an integrated approach to tumor treatment. The goal is to create a user interface with which a tumor can be punctured under MRI guidance in such a targeted manner that simulation predicts destruction with a safety margin. This plan is then compared to temperature measurements in real time to ensure complete ablation with a safety margin (A0 ablation).

In summary, a number of tools and user interfaces are available for conducting percutaneous interventions under MRI guidance. Some of the presented methods have already proven their value in clinical use. The improvement of the interactive user interface and the development of intuitive operating concepts will further simplify workflows during MR-guided puncture and ablation so that these procedures can be performed even more easily and safely.

\section{Thermal ablation methods (LITT, RFA, MWA, CA) and noninvasive temperature measurement for monitoring results}

Minimally invasive thermoablation treatments including laserinduced thermal therapy (LITT), radiofrequency ablation (RFA), microwave ablation (MWA), and cryoablation (CA) have become established as efficient and precise methods for the coagulation of various tumors and have been used for a number of years in the clinical routine. According to the literature, the use of these methods for tumor treatment achieved median survival rates of 33.7 (LITT), 33.2 (RFA) and 29.5 (MWA) months [29] and a positive response rate of $98.2 \%$ (LITT), $97 \%$ (RFA) and $62.5 \%$ (MWA) [30].

Compared to other imaging methods, MRI is characterized by superior soft tissue contrast, multiplanar visualization, and a lack of ionizing radiation. As a result of the adequate differentiation and visualization of soft tissues, MRI is becoming increasingly important in early diagnostic imaging. An additional, albeit but not unique, advantage is that MRI is a completely noninvasive treatment monitoring method. As a result of such MR-guided monitoring methods, online display of the coagulation region and the temperature change can be achieved allowing better planning of any necessary repositioning of the transducer and thus control of the entire thermoablation treatment. Moreover, MR-compatible applicators for use in LITT, RFA, MWA, and CA methods under MRI guidance have been developed in recent years. Precise clinical data and broad experience regarding these MR-guided methods are already available [31 - 36].

MR thermometry is currently the most successful noninvasive method for temperature monitoring during treatment. An ablation procedure can be controlled based on temperaturedependent MRI parameters, such as proton resonance frequency (PRF), spin-lattice relaxation time (T1), diffusion coefficients, and the chemical shift of an exogenous sample ( $\triangleright$ Fig. 1 ). The PRF method is preferred due to its independence from tissue type and its robustness $[36,37]$. The PRF method is based on the temperature-dependent phase change that allows calculation of the temperature difference (in relation to the phase position in the reference image prior to heating). As a result of real-time 
MR thermometry, the temperature change achieved during treatment can be determined and the size and position of the coagulation region can be verified. However, MR thermometry is currently limited by the relatively long acquisition time of several minutes on the MRI scanner and artifacts in moving organs. The literature reports temperature accuracy of approx. $0.2^{\circ} \mathrm{C}$ for in-vivo measurement in the brain [36], $2^{\circ} \mathrm{C}$ for in-vivo measurement in the liver [38] and $0.7^{\circ} \mathrm{C}$ for ex-vivo measurement in pig liver [37].

Due to the greater demand for thermal ablation methods, further development and improvement of MR thermometry is desirable for optimal treatment control. This will result in an increase in patient safety and thus in long-term use of thermotherapy methods in the clinical routine.

\section{Focal therapy of prostate cancer}

MR-guided methods for focal therapy of prostate cancer, especially laser ablation, cryotherapy, and focused ultrasound, are becoming a promising option for treating low-grade to medium-grade tumors as an alternative to active monitoring and prostatectomy. Targeted treatment of the index tumor while protecting sensitive neighboring structures makes it possible to reduce treatmentassociated side effects such as erectile dysfunction and incontinence [39].

The safety and feasibility of the indicated methods was able to be proven in various phase I studies with a low side effect profile in each case [40-45]. In addition, further studies (evidence level <2b) with short to medium-term follow-up intervals of 6 12 months were able to show complete tumor ablation for laser ablation in approx. $75 \%$ of cases and for focused ultrasound in approx. $83 \%$ of cases [46]. At the same time, initial study results show that tumor relapse after radiotherapy or prostatectomy can be treated relatively safely with cryotherapy [47]. For example, 7 of 10 patients were tumor-free after 12 months in one study [48].

The advantages of MRI compared to ultrasound (US) or MRI-US fusion for intervention control can be summarized in four points: 1. Targeted preinterventional patient selection via multiparametric MRI and exact (re-) identification of the index lesion. 2. Accurate placement of the ablation tools in the target lesion virtually in real time. 3. Real-time visualization of the coagulation region for complete selective tumor ablation via MR thermometry during laser ablation or via focused ultrasound or T1-weighted sequence during cryotherapy (monitoring). 4. Direct review and documentation of ablation results after final contrast agent administration (monitoring of results).

The disadvantages of MRI are the comparatively high cost and the long intervention times of approx. $1-6$ hours [41, 45]. A reproducible reduction of the intervention time to less than three hours would make greater use of focal therapy in the clinical routine more realistic. MR-compatible robotic systems for automated intervention control could contribute to this [49].

MR-guided focal therapy has achieved good results and provides a possible solution to a central problem in the current treatment regime, i. e. the overtreatment of low- and mediumgrade prostate cancer. For focal therapy to be able to become

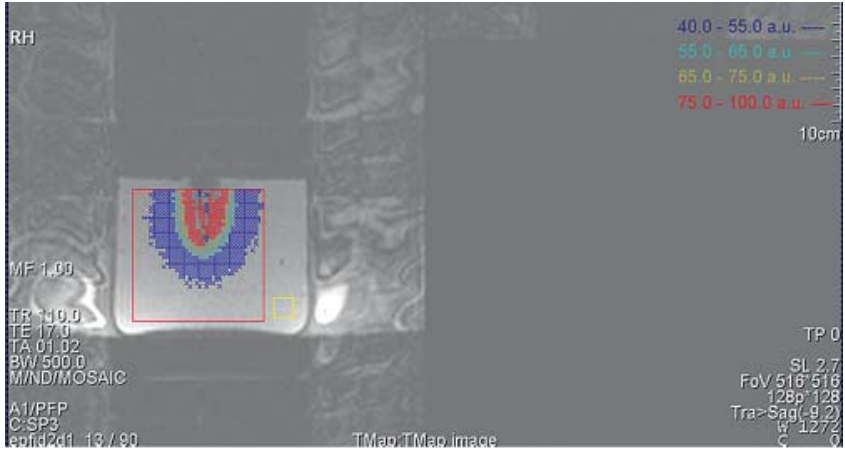

- Fig. 1 MRI basel temperature measurement during LITT in a gel phantom. Temperature is coded by different colors. The image has been acquired with an echo planar imaging (EPI) sequence.

established in the future as an alternative, studies over longer periods and involving larger groups of patients are needed.

\section{MR-guided focused ultrasound}

MR-guided focused ultrasound (MR-HIFU, MRgFUS) has been available for clinical application in various diseases for more than 10 years. The basic idea is to focus ultrasound waves from multiple sources on one point in the body thus transferring very high energy to the target region. Systems with several hundred elements that have a slightly lower frequency (approximately $1 \mathrm{MHz}$ ) compared to diagnostic ultrasound but achieve a significantly higher average intensity (up to $10000 \mathrm{~W} / \mathrm{cm}^{2}$ ) in the target volume are typically used [50]. Maximum penetration depths of up to $15 \mathrm{~cm}$ can be achieved with currently available systems. The most important effect of focused ultrasound is the local heating of the tissue in the target region with coagulation necrosis occurring starting at a temperature of approximately $60^{\circ} \mathrm{C}$. In addition, there are also mechanical and chemical effects that can be used in different applications.

In principle, treatment can also be performed under ultrasound guidance. However, the use of MRI has definite advantages. On the one hand, three-dimensional MR imaging in combination with the excellent soft tissue contrast makes it possible to determine the exact location of the target lesion. On the other hand, direct treatment control and targeted treatment guidance can be achieved by MR thermometry. The definite advantage compared to all other interventional methods for local destruction of tissue is that needles and catheters are not necessary and the integrity of the body surface is maintained.

The most established and best evaluated application of MR-HIFU is the treatment of uterine fibroids ( $\triangleright$ Fig. 2 ). Treatment takes approximately 2 to 3 hours, can be performed on an outpatient basis under analgosedation and most patients can usually resume normal activities the following day [51]. The method has undergone further technical development in recent years to improve safety and efficiency $[52,53]$. Clinical studies show that the results are comparable with other uterus-preserving treatment methods [54]. In the meantime, other benign tumors (e. g. 

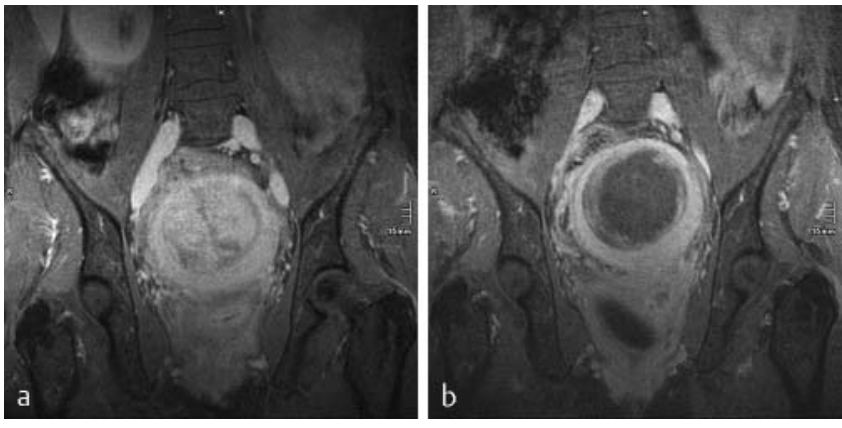

- Fig. 2 Contrast enhanced T1-weighted sequence with fat saturation prior $\mathbf{A}$ and after $\mathbf{B}$ HIFU. The large myoma centrally within the uterus enhances prior treatment. After therapy the non-enhancing areas of approximately $85 \%$ of the myoma volume, correspondes to coagulation-necrosis.

fibroadenomas, osteoid osteomas) have also been successfully treated with focused ultrasound [55].

Based on experience treating benign tumors, there are now numerous experimental studies and small patient series regarding the treatment of malignancies [56], in particular, pancreatic tumors, breast cancer, prostate cancer, renal tumors, liver tumors, and brain tumors. A further oncological application that is possible with currently available systems is the treatment of bone metastases [57]. However, in this application, not the complete destruction of the tumor but rather the treatment of pain in the palliative situation is the first priority.

In the applications described to date, focused ultrasound is always used for the direct destruction of the tissue in the target region. There are numerous additional possible therapeutic applications. For example, local hyperthermia can be generated in malignant tumors by means of HIFU to increase sensitivity to radiation or chemotherapy.

A further approach is the use of HIFU effects for the local application of medications [50]. For example, thermosensitive liposomes that release the medication contained in the liposomes in the target region in the case of mild hyperthermia without thermal damage to the tissue can be used for this purpose. Another approach uses the mechanical properties (acoustic cavitation) of ultrasound waves to temporarily increase the permeability of cell membranes (sonoporation). A clinically interesting application is the temporary opening of the blood-brain barrier, as has been able to be successfully performed in animal experiments, to apply, for example, dopamine receptor antibodies or chemotherapeutic agents in a targeted manner.

\section{Financial feasibility of MR-guided interventions}

\section{Status analysis}

The challenge regarding oncological interventions under MR guidance (iMRI) is that operating the MRI system alone or as a hybrid system initially results in an increase in primary and secondary costs compared to conventional methods in angiography, ultra- sound, and computed tomography. However, the method provides better soft tissue contrast and can be directly combined with excellent functional imaging. For this reason, the procedure for performing MR-guided interventions cannot be simply transferred from current standard concepts in interventional radiology but rather must be based on general conditions such as the case mix index of the disease, the complexity of the treatment concept, and billing using numbers from comparable medical services.

Therefore, oncological interventions such as interventional thermoablation and navigation-assisted implantation of radioactive iodine seeds are suitable particularly for iMRI with cost coverage.

\section{Calculation using oncological interventions as an example}

\section{Organization}

To ensure efficient utilization of an MRI system, it is ideal to combine periodically performed interventions with corresponding diagnostic imaging covered by reimbursement. Calculations have shown that use of the system for interventions 2 days a week in combination with planning and follow-up imaging on the other days results in amortization of the innovation costs over a period of $8-10$ years in a conservative analysis with slow dynamics of development with gradual doubling times over multiple years. It must be assumed that the dynamics depend on the strategic business model that develops over the course of the years from the continuation of the medical indications on the one hand and the influx of innovations on the other hand. This continuous influx of innovations ideally results from a test environment established in parallel to clinical iMRI to prevent downtime. An example of this is the research campus M2OLIE in Mannheim at which a clinical iMRI suite as well as a purely experimental intervention suite are set up to develop and test technical innovations in the field of navigation and robotic assistance systems in a targeted manner.

In addition to usage times, the expenses for infrastructure must be calculated. These can be divided into conversion costs, personnel costs for physicians and medical-technical personnel, and ongoing costs for power and maintenance. In the above usage model, these costs can be shown within the targeted refinancing period of $8-10$ years. The system must be used in a regulated manner for the individual treatment units and diagnostic examinations for preparation, monitoring, and follow-up to ensure efficient use of these resources and to prevent longer idle times of the iMRI system.

\section{Procedures}

For the above refinancing, oncological interventions using minimally invasive ablative procedures (thermoablation, irreversible electroporation, IRE, etc.) are particularly suitable since these can be represented as partial organ resection. Interventions involving the kidney such as ablation of renal cell carcinomas in inoperable patients or patients with a single kidney, ablation of bronchial carcinomas up to a size of approx. $2 \mathrm{~cm}$ with a curative intent or 
ablation of lung metastases to stabilize patients with oligometastases are particularly relevant to reimbursement. In contrast, interventions involving the liver are less cost-covering since the reimbursement is usually significantly less than the material costs of the thermoablative methods used.

With respect to other concepts for minimally invasive tumor therapy, cooperative interdisciplinary models are important for targeted optimization of the reimbursement structure. An increasingly common indication is the interventional implantation of radioactive iodine seeds in cooperation with radiotherapy/radiation oncology. In iMRI, these methods can be used alone, e. $g$. for the prostate or in the case of unresectable recurrent rectal cancer in the small pelvis, to increase precision regarding the coverage of the clinical target volume, or in combination with radiological interventional thermoablative methods in multifocal lesions with a partially infiltrative growth pattern, e. g. in cholangiocellular carcinomas with intrahepatic metastases. It is important for the compensation structure that brachytherapy in the region of the pelvis is able to be billed analogously to conventional radiotherapeutic methods and the added technical costs for increasing precision by means of iMRI can be covered.

\section{Consideration of future developments}

To ensure refinancing of the iMRI system possibly as a hybrid suite with an additional angiography system over the long term, it is important for radiology to be positioned as an equal clinical partner in an innovative clinical oncological environment in the context of patients with oligometastases to ensure a continuous flow of patients in radiology in cooperative models. In addition to the purely case-based reimbursement values, interdisciplinary treatment of oncological diseases in the stage of oligometastases results in an increasingly complex patient spectrum that can be potentially represented in the case mix index and in the corresponding DRG flat rates. The following shows a patient with prostate cancer and a liver metastasis to be ablated with a length of stay of 3 days as an example:

1. Ablation - liver (length of stay: 3 days):

a) Diagnoses: Secondary malignant neoplasm of liver (C78.7), malignant neoplasm of prostate (C61)

b) Procedures: $5-501.53, \mathrm{CT} / \mathrm{MRI}$

c) DRG H41C, CMI $=1.604$

d) At present, this is reimbursed at an amount of $4536.12 €$ in Baden-Württemberg.

In contrast, the optimization of iMRI systems or combined hybrid suites with respect to supporting hardware and software for navigation, the integration of assistance systems and data fusion can require the integration of multiple manufacturers to create innovative individual components. The expenditure including downtime and personnel for creating interfaces or addressing regulatory aspects in accordance with the Medical Device Directive can result in significant costs that can be difficult to calculate. Manufacturers are requested to search for integrative solutions in cooperative models as, for example, in the case of the development environments M2OLIE (Mannheim) and STIMULATE (Magdeburg/Hannover) of the research campuses that make possible major initiatives of the Federal Ministry of Education and Research.

\section{Developments for a general cost reduction of iMRI}

The use of $\mathrm{MMRI}$ is expected to result in a reduction in morbidity due to the more precise and gentle interventions with potential shortening of the length of stay in the short term and in a reduction of interventions in case of relapse due to improved soft tissue contrast in the medium to long term. The shortening of the length of stay frees up resources for treating additional patients In particular, simplification of the spatially limited options regarding navigation in iMRI or shortening of the current navigation times in hybrid suites using complicated X-ray equipment will result in an increase in efficiency. One possibility here is the use of ultrasound systems with which a majority of real-time interventions could be performed outside the iMRI system using image fusion on the basis of MRI image data acquired before and after.

\section{Conclusion and outlook}

Interventional MRI is established for diagnostic imaging for many indications in patients with suspicion of a malignancy. It is comprehensively used for breast biopsy and is being increasingly used for prostate biopsy. Decisions regarding biopsy of other organs, such as the liver, are typically made on a case-by-case basis when other modalities are difficult or impossible to use. Interventional MRI offers unique advantages for image-guided ablation due to the exact visualization of tumor borders and temperature sensitivity. The cost analysis for the treatment of tumors and metastases shows that interventional MRI can be performed in a cost-covering manner also in this application area. This is an important requirement for broader use.

\section{Conflict of Interest}

The authors declare that they have no conflict of interest.

\section{References}

[1] Barkhausen J, Kahn T, Krombach GA et al. White paper: Interventionelle MRT: Status Quo und Entwicklungspotenzial unter ökonomischen Perspektiven, Teil 1: generelle Anwendungen. Fortschr Röntgenstr 2017; 189: 611 - 623 doi: $10.1055 / \mathrm{s}-0043-110011$

[2] Weiss CR, Nour SG, Lewin JS. MR-guided biopsy: a review of current techniques and applications. J Magn Reson Imaging 2008; 27: 311-325

[3] Siegmann-Luz KC, Bahrs SD, Preibsch $\mathrm{H}$ et al. Management of breast lesions detectable only on MRI. Fortschr Röntgenstr 2014; 186: 30 - 36

[4] Fischbach F, Bunke J, Thormann M et al. MR-guided freehand biopsy of liver lesions with fast continuous imaging using a 1.0-T open MRI scanner: experience in 50 patients. Cardiovasc Intervent Radiol 2011; 34: $188-192$

[5] Schwab SA, Kuefner MA, Adamietz B et al. MRI-guided core biopsy of the prostate in the supine position - introduction of a simplified technique using large-bore magnet systems. Eur Radiol 2013; 23: 1415-1419

[6] Kuhn JP, Langner S, Hegenscheid $\mathrm{K}$ et al. Magnetic resonance-guided upper abdominal biopsies in a high-field wide-bore 3-T MRI system: feasibility, handling, and needle artefacts. Eur Radiol 2010; 20: 2414-2421 
[7] Zangos S, Eichler K, Wetter A et al. MR-guided biopsies of lesions in the retroperitoneal space: technique and results. Eur Radiol 2006; 16: 307 312

[8] Stattaus ], Maderwald S, Baba HA et al. MR-guided liver biopsy within a short, wide-bore 1.5 Tesla MR system. Eur Radiol 2008; 18: 2865-2873

[9] Xu D, Herzka DA, Gilson WD et al. MR-guided sclerotherapy of low-flow vascular malformations using T2 -weighted interrupted bSSFP (T2 WiSSFP): comparison of pulse sequences for visualization and needle guidance. J Magn Reson Imaging 2015; 41: 525- 535

[10] Boll DT, Merkle EM, Lewin JS. MR-guided percutaneous sclerotherapy of low-flow vascular malformations in the head and neck. Magn Reson Imaging Clin N Am 2005; 13: 595-600

[11] Fritz J, Tzaribachev N, Thomas C et al. Evaluation of MR imaging guided steroid injection of the sacroiliac joints for the treatment of children with refractory enthesitis-related arthritis. Eur Radiol 2011; 21: 1050 - 1057

[12] Streitparth F, Walter T, Wonneberger $U$ et al. Image-guided spinal injection procedures in open high-field MRI with vertical field orientation: feasibility and technical features. Eur Radiol 2010; 20: 395-403

[13] Fritz ], Thomas C, Clasen S et al. Freehand real-time MRI-guided lumbar spinal injection procedures at $1.5 \mathrm{~T}$ : feasibility, accuracy, and safety. Am J Roentgenol 2009; 192: W161 - W167

[14] Wacker FK, Faiss S, Reither K et al. MR imaging-guided biliary drainage in an open low-field system: first clinical experiences. Fortschr Röntgenstr 2000; 172: $744-747$

[15] Porsch M, Wendler J], Fischbach F et al. Placement of percutaneous nephrostomy by open magnetic resonance imaging: clinical results and current status in urology. Urologe A 2012; 51: 1722 - 1727

[16] Rempp H, Waibel L, Hoffmann R et al. MR-guided radiofrequency ablation using a wide-bore 1.5-T MR system: clinical results of 213 treated liver lesions. Eur Radiol 2012; 22: 1972 - 1982

[17] Ritz JP, Lehmann KS, Zurbuchen $U$ et al. Improving laser-induced thermotherapy of liver metastases-effects of arterial microembolization and complete blood flow occlusion. Eur ] Surg Oncol 2007; 33: 608-615

[18] Zangos S, Melzer A, Eichler K et al. MR-compatible assistance system for biopsy in a high-field-strength system: initial results in patients with suspicious prostate lesions. Radiology 2011; 259: 903 -910

[19] Christoforou EG, Seimenis I, Andreou E et al. A novel, general-purpose, MR-compatible, manually actuated robotic manipulation system for minimally invasive interventions under direct MRI guidance. Int J Med Robot 2014; 10: $22-34$

[20] Schell B, Eichler K, Mack MG et al. Robot-assisted biopsies in a high-field MRI system - first clinical results. Fortwschr Röntgenstr 2012; 184: 42 47

[21] Wacker FK, Vogt S, Khamene A et al. An augmented reality system for MR image-guided needle biopsy: initial results in a swine model. Radiology 2006; 238: $497-504$

[22] Fritz ], Thainual P, Ungi T et al. Augmented reality visualization using image overlay technology for MR-guided interventions: cadaveric bone biopsy at 1.5 T. Invest Radiol 2013; 48: 464-470

[23] Fischer GS, Deguet A, Csoma C et al. MRI image overlay: application to arthrography needle insertion. Comput Aided Surg 2007; 12: 2-14

[24] Boss A, Rempp H, Martirosian P et al. Wide-bore 1.5 Tesla MR imagers for guidance and monitoring of radiofrequency ablation of renal cell carcinoma: initial experience on feasibility. Eur Radiol 2008; 18: 1449 1455

[25] Zangos S, Vetter T, Huebner F et al. MR-guided biopsies with a newly designed cordless coil in an open low-field system: initial findings. Eur Radiol 2006; 16: $2044-2050$

[26] Stattaus ], Maderwald S, Forsting M et al. MR-guided core biopsy with MR fluoroscopy using a short, wide-bore 1.5-Tesla scanner: feasibility and initial results. J Magn Reson Imaging 2008; 27: 1181 - 1187
[27] Rothgang E, Gilson WD, Wacker F et al. Rapid freehand MR-guided percutaneous needle interventions: an image-based approach to improve workflow and feasibility. J Magn Reson Imaging 2013; 37: 1202 - 1212

[28] Meyer BC, Brost A, Kraitchman DL et al. Percutaneous punctures with MR imaging guidance: comparison between MR imaging-enhanced fluoroscopic guidance and real-time MR Imaging guidance. Radiology 2013; 266: $912-919$

[29] Vogl T], Farshid P, Naguib NN et al. Thermal ablation of liver metastases from colorectal cancer: radiofrequency, microwave and laser ablation therapies. Radiol Med 2014; 119: 451 - 461

[30] Vogl T], Farshid P, Naguib NN et al. Thermal ablation therapies in patients with breast cancer liver metastases: a review. Eur Radiol 2013; 23: $797-804$

[31] Vogl T], Straub R, Zangos S et al. MR-guided laser-induced thermotherapy (LITT) of liver tumours: experimental and clinical data. Int J Hyperthermia 2004; $20: 713-724$

[32] Vogl T], Straub R, Lehnert T et al. Percutaneous thermoablation of pulmonary metastases. Experience with the application of laser-induced thermotherapy (LITT) and radiofrequency ablation (RFA), and a literature review. Fortschr Röntgenstr 2004; 176: 1658 - 1666

[33] Morikawa S, Naka S, Murakami K et al. Preliminary clinical experiences of a motorized manipulator for magnetic resonance image-guided microwave coagulation therapy of liver tumors. Am J Surg 2009; 198: 340 347

[34] Morrison PR, Silverman SG, Tuncali K et al. MRI-guided cryotherapy. J Magn Reson Imaging 2008; 27: 410-420

[35] Morikawa S, Naka s, Murayama H et al. MRI-Guided Microwave Ablation. Medical Radiology 2012: 389-402

[36] Kickhefel A, Roland J, Weiss C et al. Accuracy of real-time MR temperature mapping in the brain: a comparison of fast sequences. Phys Med 2010; 26: $192-201$

[37] Bazrafshan B, Hubner F, Farshid P et al. Magnetic resonance temperature imaging of laser-induced thermotherapy: assessment of fast sequences in ex vivo porcine liver. Future Oncol 2013; 9: 1039-1050

[38] Kickhefel A, Rosenberg C, Roland J et al. A pilot study for clinical feasibility of the near-harmonic 2D referenceless PRFS thermometry in liver under free breathing using MR-guided LITT ablation data. Int J Hyperthermia 2012; 28: $250-266$

[39] Valerio M, Ahmed HU, Emberton M et al. The role of focal therapy in the management of localised prostate cancer: a systematic review. Eur Urol 2014; 66: $732-751$

[40] Raz O, Haider MA, Davidson SR et al. Real-time magnetic resonance imaging-guided focal laser therapy in patients with low-risk prostate cancer. Eur Urol 2010; 58: 173-177

[41] Lindner U, Ghai S, Spensieri P et al. Focal magnetic resonance guided focused ultrasound for prostate cancer: Initial North American experience. Can Urol Assoc J 2012; 6: E283-E286

[42] Napoli A, Anzidei M, De NC et al. Real-time magnetic resonance-guided high-intensity focused ultrasound focal therapy for localised prostate cancer: preliminary experience. Eur Urol 2013; 63: 395-398

[43] Chopra R, Colquhoun A, Burtnyk M et al. MR imaging-controlled transurethral ultrasound therapy for conformal treatment of prostate tissue: initial feasibility in humans. Radiology 2012; 265: 303-313

[44] Gangi A, Tsoumakidou G, Abdelli O et al. Percutaneous MR-guided cryoablation of prostate cancer: initial experience. Eur Radiol 2012; 22: $1829-1835$

[45] Oto A, Sethi I, Karczmar G et al. MR imaging-guided focal laser ablation for prostate cancer: phase I trial. Radiology 2013; 267: 932 -940

[46] Ghai S, Trachtenberg J. In-bore MRI interventions: current status and future applications. Curr Opin Urol 2015; 25: 205-211

[47] Woodrum DA, Kawashima A, Karnes RJ et al. Magnetic resonance imaging-guided cryoablation of recurrent prostate cancer after radical 
prostatectomy: initial single institution experience. Urology 2013; 82: $870-875$

[48] Bomers JG, Yakar D, Overduin CG et al. MR imaging-guided focal cryoablation in patients with recurrent prostate cancer. Radiology 2013; 268 : $451-460$

[49] Cepek J, Lindner U, Ghai S et al. Mechatronic system for in-bore MRIguided insertion of needles to the prostate: An in vivo needle guidance accuracy study. J Magn Reson Imaging 2015; 42: 48 - 55 doi: 10.1002/ jmri.24742

[50] Phenix CP, Togtema M, Pichardo S et al. High intensity focused ultrasound technology, its scope and applications in therapy and drug delivery. J Pharm Pharm Sci 2014; 17: 136-153

[51] Ruhnke H, Eckey T, Bohlmann MK et al. MR-guided HIFU treatment of symptomatic uterine fibroids using novel feedback-regulated volumetric ablation: effectiveness and clinical practice. Fortschr Röntgenstr 2013; 185: $983-991$

[52] Kim YS, Trillaud H, Rhim H et al. MR thermometry analysis of sonication accuracy and safety margin of volumetric MR imaging-guided high-intensity focused ultrasound ablation of symptomatic uterine fibroids. Radiology 2012; 265: 627 - 637
[53] Trumm CG, Stahl R, Clevert DA et al. Magnetic resonance imagingguided focused ultrasound treatment of symptomatic uterine fibroids: impact of technology advancement on ablation volumes in 115 patients. Invest Radiol 2013; 48: 359-365

[54] Gorny KR, Woodrum DA, Brown DL et al. Magnetic resonance-guided focused ultrasound of uterine leiomyomas: review of a 12-month outcome of 130 clinical patients. J Vasc Interv Radiol 2011; 22: 857-864

[55] Geiger D, Napoli A, Conchiglia A et al. MR-guided focused ultrasound (MRgFUS) ablation for the treatment of nonspinal osteoid osteoma: a prospective multicenter evaluation. J Bone Joint Surg Am 2014; 96: $743-751$

[56] Malietzis G, Monzon L, Hand J et al. High-intensity focused ultrasound: advances in technology and experimental trials support enhanced utility of focused ultrasound surgery in oncology. Br J Radiol 2013; 86: 20130044

[57] Huisman M, Ter HG, Napoli A et al. International consensus on use of focused ultrasound for painful bone metastases: Current status and future directions. Int J Hyperthermia 2015: 1 - 9 